CASE REPORT

\title{
Pemphigus and its variants with direct immunofluorescence: Case series of 32 cases
}

\author{
Arundhathi $\mathbf{S}^{1, *}$ \\ ${ }^{1}$ Department of Pathology, All India Institute of Medical Sciences, Mangalagiri, Andhra Pradesh, India
}

\begin{abstract}
Pemphigus is a group of autoimmune vesiculobullous diseases of skin and mucous membrane. Histologically characterised by intraepidermal bulla and immunologically by circulating IgG autoantibodies targeted against keratinocytes. We are presenting 32 cases of pemphigus and its variants. The histopathologic and direct immunofluorescence (DIF) findings are described.
\end{abstract}

Keywords: pemphigus; direct immunofluorescence; intraepidermal bulla; pemphigus vulgaris

\begin{abstract}
*Corresponding author: Dr. Arundhathi S, Associate Professor, Department of Pathology, All India Institute of Medical Sciences, Old TB Sanatorium Road, Mangalagiri, Andhra Pradesh-522503, India. Mobile: +91 9449670559; Email: arundhathi19@yahoo. co.in

Received 21 April 2021; Revised 31 May 2021; Accepted 11 June 2021; Published 21 June 2021

Citation: Arundhathi S. Pemphigus and its variants with direct immunofluorescence: Case series of 32 cases. J Med Sci Res. 2021; 9(3):173-177. DOI: http://dx.doi.org/10.17727/JMSR.2021/925

Copyright: (C) 2021 Arundhathi S. Published by KIMS Foundation and Research Center. This is an open-access article distributed under the terms of the Creative Commons Attribution License, which permits unrestricted use, distribution, and reproduction in any medium, provided the original author and source are credited.
\end{abstract}

\section{Introduction}

Vesiculobullous disorders are heterogenous group of dermatosis with variable manifestations. Among these disorders pemphigus is a large group of autoimmune vesiculobullous diseases involving skin and mucous membranes. It is characterized histologically by intraepidermal bulla resulting from acantholysis and immunopathologically by in vivo bound and circulating IgG autoantibodies directed againstthecellsurface of keratinocytes[1].Pemphigus is divided into 5 types- pemphigus vulgaris (PV), pemphigus foliaceus (PF), drug-induced pemphigus, IgA pemphigus and paraneoplastic pemphigus [2]. Here we are presenting 32 cases of pemphigus along with direct immunofluorescence (DIF) findings.

\section{Case series}

Here we are presenting 32 cases of pemphigus and its variants. Out of these 32 cases, 26 were of PV (81.25\%), 4 were pemphigus foliaceous $(12.5 \%)$ and 2 of pemphigus erythematosus (6.25\%). Eight cases each (25\%) were in the age group of 20-29 and $40-49$ years, 6 each (18.75\%) were in the age group 
of 30-39 and 50-59 years, $3(9.4 \%)$ in the age group of 60-69 years and one (3.1\%) was above 80 years. Blisters were present in 27 (84.4\%) cases. Burning sensation was the chief complaint in 21 out of 26 cases $(80.8 \%)$, followed by pain $(4 / 26,15.4 \%)$ and itching $(1 / 26,3.9 \%)$. Burning sensation was seen in $3 \mathrm{PF}$ patients $(3 / 4,75 \%)$. One $(50 \%)$ patient of pemphigus erythematosus (PE) presented with photosensitivity. Nikolsky sign was positive in 22 (84.6\%) cases of PV, 2 (50\%) cases of PF and 1 (50\%) case of PE. Oral mucosal involvement was seen in 22 (84.62\%) cases of PV and one (25\%) case of PF.

On histopathology, 25(96.2\%) cases of PV showed suprabasal bullae (Figure 1) and 3(75\%) of PF and one case $(50 \%)$ of PE showed subcorneal bulla (Figure 2). There was no separation seen in one case of PE. Tomb stone appearance was seen in 23 (88.5\%) cases of PV. Epidermal changes noted in pemphigus group are shown in Table 1. Dermal and perivascular inflammation were the common dermal changes seen (Tables 2\&3). Predominant inflammatory cells in the blister cavity were neutrophils (46.2\%) in PV.

Direct immunofluorescence (DIF) was performed in all 32 cases of pemphigus. Majority of them (29/32, 90.6\%) were DIF positive and showed deposition of immunoglobulins in squamous intercellular spaces giving fish net appearance (Figure 3). IgG deposition was seen in 19 cases (59.4\%) and both IgG and C3 deposition in 10 cases (31.25\%). There was discordance between histopathology and DIF findings in two cases of PV and one case of PF. In all these 3 cases DIF was negative. Thus DIF assisted in arriving at a diagnosis in 29 cases of pemphigus. Thus, DIF had a sensitivity of $90.63 \%$ in diagnosing pemphigus group of vesiculobullous lesions in this study. The histopathological features were classical in these cases and thus histopathology helped to arrive at a correct diagnosis.

Table 1: Epidermal changes seen in pemphigus and its variants.

\begin{tabular}{|llcllll|}
\hline & \multicolumn{5}{c|}{ Epidermal changes } \\
\cline { 2 - 7 } & $\begin{array}{c}\text { Tomb stone } \\
\text { Fppearance }\end{array}$ & Villi & Hyperkeratosis & Acanthosis & Dyskeratosis & Acanthocytes \\
\hline PV & $23(88.5 \%)$ & $10(38.5 \%)$ & $2(7.7 \%)$ & $3(11.5 \%)$ & 0 & $20(76.9 \%)$ \\
PF & 0 & $1(25 \%)$ & 0 & 0 & $1(25 \%)$ & $3(75 \%)$ \\
PE & 0 & 0 & 0 & 0 & 0 & $2(100 \%)$ \\
\hline
\end{tabular}

Table 2: Dermal changes seen in pemphigus and its variants.

\begin{tabular}{|ccccc|}
\hline \multirow{2}{*}{ Final diagnosis } & \multicolumn{4}{c|}{ Dermal changes } \\
\cline { 2 - 5 } & Dermal edema & $\begin{array}{c}\text { Dermal } \\
\text { infiltration }\end{array}$ & $\begin{array}{c}\text { Perivascular } \\
\text { inflammation }\end{array}$ & Adnexal inflammation \\
\hline PV & $1(3.9 \%)$ & $22(99.4 \%)$ & $16(61.5 \%)$ & 0 \\
PF & 0 & $4(100 \%)$ & $2(50 \%)$ & 0 \\
PE & 0 & $2(100 \%)$ & 0 & 0 \\
\hline
\end{tabular}

Table 3: inflammatory cells in blister seen in pemphigus and its variants.

\begin{tabular}{|cccccc|}
\hline \multirow{2}{*}{ Final diagnosis } & \multicolumn{5}{c|}{ Inflammatory cell in the blister } \\
\cline { 2 - 6 } & Absent & Neutrophils & Lymphocytes & Eosinophils & Macrophages \\
\hline PV & $10(38.5 \%)$ & $12(46.2 \%)$ & $2(7.7 \%)$ & $2(7.7 \%)$ & 0 \\
PF & $1(25 \%)$ & $2(50 \%)$ & $1(25 \%)$ & 0 & 0 \\
PE & $2(100 \%)$ & 0 & 0 & 0 & 0 \\
\hline
\end{tabular}


Table 4: DIF findings.

\begin{tabular}{|ccccccc|}
\hline \multirow{2}{*}{ Final diagnosis } & \multicolumn{5}{c|}{ Antibody deposition } \\
\cline { 2 - 7 } & $I g G$ & $\operatorname{Ig} M$ & $\operatorname{IgA}$ & C3 & Both IgG \& C3 & Negative \\
\hline $\mathrm{PV}$ & $15(57.7 \%)$ & 0 & 0 & 0 & $9(34.6 \%)$ & $2(7.7 \%)$ \\
$\mathrm{PF}$ & $2(50 \%)$ & 0 & 0 & 0 & $1(25 \%)$ & $1(25 \%)$ \\
$\mathrm{PE}$ & $2(100 \%)$ & 0 & 0 & 0 & 0 & 0 \\
\hline
\end{tabular}

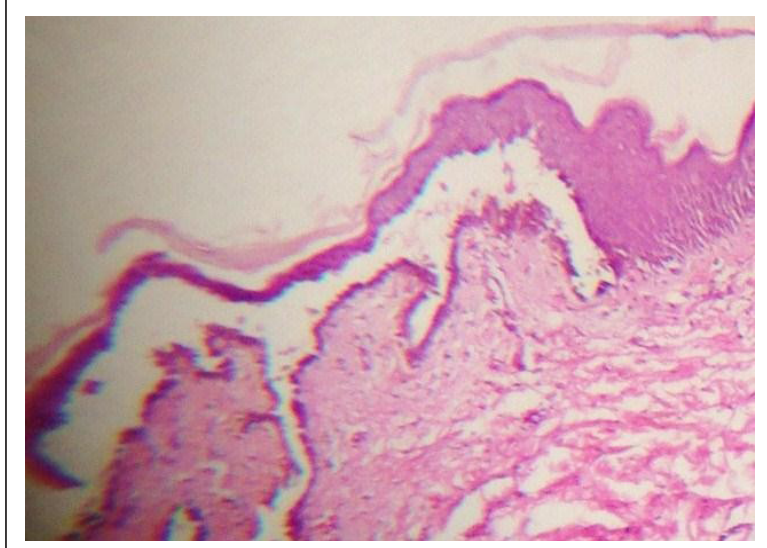

Figure 1: Suprabasal blister with tombstone appearance (H\&E, $10 \times 10 x)$.

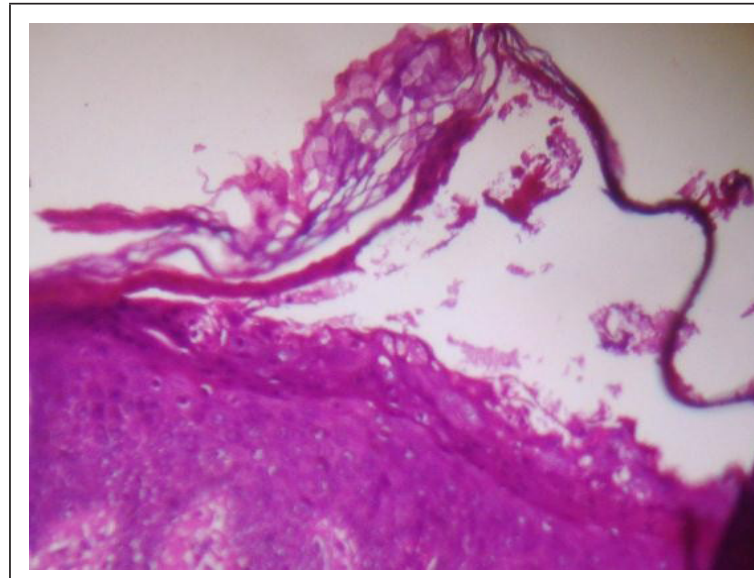

Figure 2: Subcorneal bulla (H\&E, 10 x 10X).

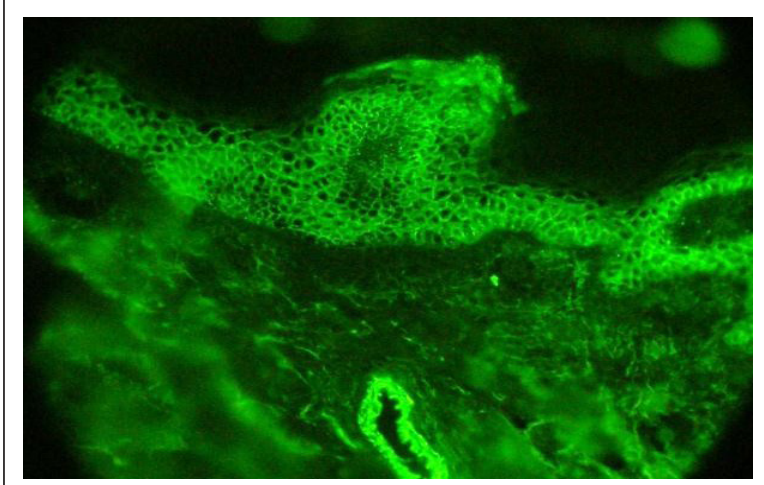

Figure 3: DIF showing full thickness fish net appearance.

\section{Discussion}

Vesiculobullous lesions of skin are heterogenous group of dermatoses and has protean manifestations. In our study over a period of two years we diagnosed 32 cases of pemphigus group. McBride (1777) first recorded a case of pemphigus and Wichmann coined the term "pemphigus" [3]. Pemphigus group is a group of autoimmune blistering disease of skin and mucosa characterised by intraepidermal bulla formed due to acantholysis and presence of in vivo bound and circulating IgG autoantibodies targeted against keratinocyte surface [1].

Pemphigus is divided into 5 types: (1) Pemphigus vulgaris, with its reactive state, pemphigus vegetans, (2) Pemphigus foliaceus, with its lupus- like variant, pemphigus erythematosus and its endemic variant, fogo selvage, (3) Drug- induced pemphigus, (4) IgA pemphigus, (5) Paraneoplastic pemphigus [2].

Civatte (1943) identified the histopathologic hallmark of pemphigus group and labelled it as acantholysis. He described intraepidermal bulla formation in PV, pemphigus vegetans and PF and these pathologic findings separated pemphigus from other cutaneous vesiculobullous diseases [4]. Beutner and Jordon in 1964 detected autoantibodies in sera of patients with pemphigus which are reactive with intercellular substance of skin and mucosa by indirect immunofluorescence (IIF). Later they showed these autoantibodies can be demonstrated by DIF too [5]. In 1941, Coons et al., developed the technique of immunofluorescence.

The target antigens in pemphigus is located in desmosomes. Desmoglein 1 expressed in upper epidermis is the target antigen in PF. Desmoglein 3 which is located in spinous layer of epidermis and mucous membrane is the target in PV [6]. Some cases of IgA pemphigus have autoantibodies to the desmocollins. 
In our observation, $\mathrm{PV}$ was the commonest among pemphigus group. This was in accordance with observation by Simon et al [7]. It is known to be associated with HLA-DRB $1 * 04$ and DRB1*14 [8]. It is also known to be associated with other autoimmune diseases like systemic lupus erythematosus, rheumatoid arthritis, Hashimotos's thyroiditis, Sjogren's syndrome and myasthenia gravis [9]. Oral mucosal involvement was seen in $22(84.62 \%)$ cases of PV in our study, which is similar to study by Handa et al [10]. We noted that 25(96.2\%) cases of PV showed suprabasal bullae similar to Handa et al [10], and $23(88.5 \%)$ cases had tomb stone appearance which was higher than Arya et al [11]. DIF was positive in $24(92.31 \%)$ cases of PV, out of which 15 (57.7\%) showed IgG deposition, 9(34.6\%) cases showed both IgG \& C3 deposition and 2 (7.7\%) cases were negative. This was in accordance with study by Chams-Davatchi et al [12]. This showed that the most confirmatory investigation may be negative and thus the diagnosis depends on histopathology. The cause for negative results may be due to technical error, treatment status or biopsy site selected [13].

Pemphigus vegetans (PVe) is an uncommon variant $(1-2 \%)$ of PV. It is characterised by flexural vegetating erosions [8]. Hallopeau and Neumann are the two subtypes of PV [14]. Verrucous epidermal hyperplasia, eosinophilic spongiosis and pustules are histological features of Neumann type. Hallopeau type is characterised by pustules, acantholysis and suprabasal clefting [2]. DIF is similar to PV [8]. Unfortunately we did not encounter a single case of PVe.

PF known as superficial pemphigus characterised by subcorneal blister accounts for $10-20 \%$ cases of pemphigus [8]. The histological features of $\mathrm{PF}$ are eosinophilic spongiosis, subcorneal blisters, dyskeratotic acanthocytes [2]. Full thickness or superficial squamous intercellular IgG deposition was seen on DIF [15]. In our study we reported 4 cases of PF accounting for $12.5 \%$ of pemphigus group. Compared to study by Arya et.al, the number of PF cases were less probably due to small sample size [11]. We noted 3 (75\%) cases showing subcorneal bulla and acanthocytes which was similar to study by Fernandez et al. DIF was positive in 3 cases (75\%) and was similar to PV. DIF was $100 \%$ positive in study by Inchara et al [16] and Kanwar et al [17] showed $100 \%$ DIF positive.
Pemphigus erythematosus described by Senar and Usher is a variant of $\mathrm{PF}$ [8]. Lesions consists of scaling and crusting resembling lupus erythematosus. Positive lupus band test and intercellular deposition of IgG and C3 is noted in 75\%. In a study by American et al antinuclear antibodies (ANA) was seen in 30$80 \%$ [18]. In our study we identified 2 cases of PE and one of them presented with photosensitivity. We observed subcorneal bulla in one case and both cases showed deposition of IgG in intercellular spaces but there was no full house effect or positive lupus band.

Degos in 1969 first described drug- induced pemphigus in patients using D- penicillamine. Drug induced and drug triggered pemphigus are two separate entities [19]. Autoimmune factors play an important role in drug induced pemphigus with regression of lesions on removal of offending drug. Whereas in drug- trigerred pemphigus, the drug stimulates the occurrence of active disease [20]. Drugs induced are due to penicillamine, captopril, ACE inhibitors, nifedipine, penicillins, cephalosporins, pyrazolone derivatives and rifampicin [19]. Clinically, histopatholoically and immunologically similar to PF or PV [21].

IgA pemphigus are characterised by pustules and IgA deposition. Two types are subcorneal pustular dermatosis type (SPD) and the intraepidermal neutrophilic dermatosis type (IEN) based on level of pustules [8]. IgA deposition in squamous intercellular substance is seen on DIF [22].

Paraneoplastic pemphigus is a variant of pemphigus associated with neoplasms. It is distinct from PV and PF clinically, immunologically and histologically [23]. B cell lymphoproliferative disorders, chronic lymphocytic leukemia, Castleman's disease, sarcomas and thymomas are known to be associated with it [24]. Stomatitis is the characteristic feature of paraneoplastic pemphigus along with blisters, erosions and target lesions [25]. Histopathologically characterised by suprabasal blister, dyskeratosis, acantholysis, basal vacuolation and exocytosis of inflammatory cells. Intercellular IgG and complement deposition with or without linear granular complement deposition along basement membrane zone (BMZ) on DIF is seen [26]. Unfortunately we didn't encounter a single case of drug induced, IgA or paraneoplastic pemphigus. The cause may be 
small sample size or geographical variations. A large sample size may throw more light on these three variants of pephigus.

\section{Conclusion}

Pemphigus group of dermatosis are commonly encountered in clinical practice. They pose a great economic burden increasing the morbidity and mortality. Identification of the variant in this group helps to treat the patient efficiently. Histopathology and DIF findings together compliment each other in arriving at a definite diagnosis.

\section{Conflicts of interest}

Author declares no conflicts of interest.

\section{References}

[1] Tudesman LB, Stanley JR. Disorders of epidermal and dermal epidermal cohesion and vesicular and bullous disorders. In: Wolff K, Goldsmith LA, Katz SL, Gilchrist BA, Leffell DJ ed. Fitzpatricks Dermatology in General Medicine, 7th edition. New York: Mc Graw Hill, 2008:447-504.

[2] Wu H, Schapiro B, Harrist TJ. Noninfectious vesiculobullous and vesiculopustular diseases. In: Elder D, Elenitsas R, Johnson BL, Murphy GF, ed. Lever's histopathology of the skin, 9th edition. Philadelphia: Lippincott Williams and Wilkins, 2005:243-291.

[3] Singh R, Pandhi RK, Pal D, Kalla G. A clinicopathological study of pemphigus. Indian J Dermotol Venereol Leprol. 1973; 39(3):126-132.

[4] Hardy KM, Perry HO, Pingree GC, Kirby TJ, Minn R. Benign mucous membrane pemphigoid. Arch Dermatol. 1971; 104(5):467-475.

[5] Fitzspatrick RE, Newcomer YD. The correlation of disease activity and antibody titers in pemphigus. Arch Dermatol. 1980; 116(3):285-290.

[6] Kowalczyk AP, Anderson JE, Borgwardt JE, Hashimoto T, Stanley JR, et al. Pemphigus sera recognise conformationally sensitive epitopes in the amino- terminal region of desmoglein. J Invest Dermatol. 1995; 105(2):147-152.

[7] Simon DG, Krutchkoff D, Kaslow RA, Zarbo R. Pemphigus in Hartford country, Connecticut, from 1972 to 1977. Arch Dermatol. 1980; 116(9):1035-1037.

[8] Wojnarowska F, Venning VA. Immunobullous diseases. In: Burns T, Brethnach S, Cox N, Griffiths C, ed. Rook's Textbook of Dermatology, 8th edition. Oxford: Wells Blackwell, 2010: 40:1-40.

[9] Firooz A, Mazhar A, Ahmed AR. Prevalence of autoimmune diseases in the family members of patients with pemphigus vulgaris. J Am Acad Dermatol. 1994; 31(3 Pt 1):434-437.

[10] Handa F, Aggarwal RR, Kumar R. A clinical study of 85 cases of pemphigus. Indian J Dermotol Venereol. 1973; 39(3):106111.

[11] Arya SR, Valand AG, Krishna K. A clinico-pathological study of 70 cases of pemphigus. Indian J Dermotol Venereol Leprol. 1999; 65(4):168-171.

[12] Chams-Davatchi C, Valikhani M, Daneshpazhooh M, Esmaili N, Balighi K, et al. Pemphigus: analysis of 1209 cases. Int J Dermatol. 2005; 44(6):470-476.
[13] Arundhathi S, Ragunatha S, Mahadeva KC. A crosssectional study of clinical, histopathological and direct immunofluorescence spectrum of vesiculobullous disorders. J Clinic Diag Res. 2013; 7(12):2788-2792.

[14] Ahmed AR, Blose DA. Pemphigus Vegetans: Neumann type and Hallopeau type. Int J Dermatol. 1984; 23:135-141.

[15] Bystryn JC, Abel E, Defeo C. Pemphigus foliaceus: subcorneal intercellular antibodies of unique specificity. Arch Dermatol. $1974 ; 110: 857$.

[16] Inchara YK, Rajalakshmi T. Direct immunofluorescence in cutaneous vesiculobullous lesions. Indian J Pathol Microbiol. 2007; 50(4):730-732.

[17] Kanwar AJ, De D. Pemphigus in India. Indian J Dermatol Venereol Leprol. 2011; 77(4):439-449.

[18] American ML, Ahmed AR. Pemphigus erythematosus: presentation of four cases and review of the literature. J Am Acad Dermatol. 1984; 10(2 Pt 1):215-222.

[19] Brenner S, Wolf R, Ruocco V. Drug-induced pemphigus: A survey. Clin Dermatol. 1993; 11(4):501-505.

[20] Wolf R, Tamir A, Brenner S. Drug-induced versus drugtriggered pemphigus. Dermatologica. 1991; 182(4):207210.

[21] Pisani M, Ruocco V. Drug induced pemphigus. Clin Dermatol. 1986; 4(1):118-132.

[22] Hodak E, David M, Ingber A, Rotem A, Hazaz B, et al. The clinical and histopathological spectrum of IgA- pemphigus: a report of two cases. Clin Exp Dermatol. 1990; 15(6):433437.

[23] Anhalt GJ, Kim SC, Stanley JR, Korman NJ, Jabs DA, et al. Paraneoplastic pemphigus: an autoimmune mucocutaneous disease associated with neoplasia. N Engl J Med. 1990; 323(25): 1729-1735.

[24] Kimyai-Asadi A, Jih MH. Paraneoplastic pemphigus. Int J Dermatol. 2001; 40(6):367-372.

[25] Hoss DM, Shea CR, Grant-Kels JM. Neutrophilic spongiosis in pemphigus. Arch Dermatol. 1996; 132(3):315-318.

[26] Horn TD, Anhalt GJ. Histologic features of paraneoplastic pemphigus. Arch Dermatol. 1992; 128(8):1091-1095. 